\title{
Hipótesis sobre un topónimo habanero
}

\author{
A la memoria de mi padre, por \\ aquellas tardes de domingo. \\ [...] la toponimia es un importante \\ auxiliar de la Historia. Cuando \\ esta calla, aquella habla [...] \\ CLAUDIO SÁNCHEZ-ALBORNOZ
}

En la ciudad de La Habana existe una zona tradicionalmente conocida como La Habana Vieja. Es un área de aproximadamente 4,9 kilómetros cuadrados, antiguo recinto amurallado de la capital colonial, que en 1982 fue incluida por la UNESCO en la Lista del Patrimonio Mundial.

Dentro de esa zona, rica en valores arquitectónicos de cinco siglos, hay una sola y pequeña elevación del terreno, de apenas 8,5 metros de altura sobre el nivel del mar. Según algunos historiadores locales, desde el siglo XVI hasta nuestros días esa colina ha sido conocida sucesivamente por tres nombres surgidos de manera espontánea: el Cayaguayo, la Peña Pobre y la Loma del Ángel. El objeto principal de nuestra atención será el segundo de esos topónimos, pero antes debemos hacer un bosquejo histórico general.

\section{El Cayaguayo}

La más antigua mención de este topónimo que hemos podido localizar aparece en el acta capitular de 14 de octubre de 1569. Ese día el concejo habanero mercedó a Isabel de Sepúlveda "un pedazo de monte adelante del Demajagual adonde dicen Cayaguayó" 1.

1 Habana. Ayuntamiento. Actas capitulares del Ayuntamiento de La Habana (15501578). Con un prefacio y estudio preliminar por Emilio Roig de Leuchsenring (La Habana, 1937-1946), t. II, p. 163. La segunda mención del topónimo aparece en Ibidem, p. 301 (Cabildo de 8 de enero de 1574); pero más interesante es la tercera: el 30 de diciembre de 1575 el Ayuntamiento mercedeaba a Antonio Suaso, "vezino y poblador antiguo", dos pedazos de solares, uno "a las espaldas del solar de Juan Fernández, 
Diecinueve años antes, aunque sin darle nombre, los regidores ya habían manifestado su preocupación por el monte que poblaba "el camino que va de la Fortaleza a la punta", por considerarlo muy perjudicial, tanto para la salud de los vecinos como para la defensa de la villa ${ }^{2}$. A pesar de las mercedes de solares, en 1577 el lugar continuaba semidespoblado y el Cabildo acordaba tomarlo, junto con otros sitios cercanos, como ejido de la villa ${ }^{3}$, lo que no obstó para que el propio consistorio siguiera mercedando solares en él ${ }^{4}$. En el acta de 7 de febrero de 1578 aún se hace referencia a "una seja de monte questá allí" 5.

Es curioso observar que en los documentos citados no se menciona ninguna elevación del terreno. La impresión que transmiten es que se denominaba Cayaguayo a una zona boscosa existente en las afueras y al norte del núcleo poblacional, entre el asiento de la primitiva fortaleza de la villa y la boca o entrada de la bahía, sitio desde entonces conocido por La Punta.

El 22 de diciembre de 1602, el recién estrenado gobernador Pedro de Valdés informaba al Rey sobre las obras de fortificación que había acometido tan pronto como llegó a La Habana, en vista de la amenaza de ataque anglo-holandés. Al referirse específicamente a la plataforma que había construido en la ribera del castillo de la Real Fuerza, añadía que la piedra utilizada en la obra se había extraído de "el padrastro del Cayaguayo". Y agregaba: "El Padrastro del Cayaguayo Hago allanar por estar tan Alto que se sojuzga della toda esta Ciudad" ${ }^{6}$.

calle en medio, a la vanda del Cayagual, y el otro junto y pegado con el mismo solar, a las espaldas de Ysabel Ruiz, calle en medio, a la vanda del Cayaguayo". Ibidem. t. III, p. 59. Es decir, que aquí se agrega otro topónimo, Cayagual, que identifica un lugar colindante con el Cayaguayo o, probablemente, un sector de éste. Dos meses después, el Cabildo hizo nuevas mercedes en el sitio. Ibidem, pp. 68-69 (Cabildo de 10 de febrero de 1576). Por su parte, el doctor Pérez-Beato considera los topónimos Cayagyaso y Cayaguasí como variantes erróneas de Cayaguayo, achacables a la "confusa grafía" de las actas municipales, pero no menciona el topónimo Cayagual que, evidentemente, no es un error de lectura. Manuel PÉREz-BEATO, Habana antigua: apuntes históricos (La Habana: Impr. Seoane, Fernández y Cía., 1936), p. 20.

2 Ibid., t. I, v. II, p. 9. Cabildo de 10 de octubre de 1576.

3 Ibid., t. III, p. 137-138. Cabildo de 2 de agosto de 1577.

4 Ibid., pp. 161 y 166. Cabildos de 11 de octubre y 8 de noviembre de 1577.

5 Ibid., p. 195. Cabildo de 7 de febrero de 1578. Es de suponer que esta ceja de monte desapareció no mucho tiempo después por la tala que ya tenía lugar en los alrededores de la villa y que provocó el alejamiento de las zonas de abastecimiento maderero. Cfr. Julio LE RIVEREND, La Habana (Biografia de una provincia) (La Habana: Impr. El Siglo XX, 1960), p. 28.

6 Irene A. WRIGHT, Historia documentada de San Cristóbal de La Habana en la primera mitad del siglo XVIII (La Habana: Impr. El Siglo XX, 1930), p. 11, n. 7. 
Fijémonos en dos detalles: Valdés no asigna ningún nombre concreto a la elevación en sí misma. Se refiere a ella como "el padrastro del Cayaguayo", o sea, el "monte, colina o lugar alto y dominante a alguna plaza, desde el qual pueden batirla o hacerla daño los enemigos" " que estaba enclavado en la zona del Cayaguayo. El otro detalle que se infiere $-y$ más adelante volveremos sobre él- es el de su altura, obviamente muy superior a la actual. El hábil gobernador había resuelto dos problemas al unísono: obtener material para la fortificación y disminuir en algo el potencial peligro que el promontorio significaba para la defensa de la ciudad.

En realidad, esta preocupación por la importancia militar de la colina databa del siglo anterior. El 4 de mayo de 1537 la Corona había nombrado Gobernador de Cuba a Hernando de Soto, Adelantado de la Florida.

\begin{abstract}
Antes de que el capitán de Soto saliera de España, se había decidido construir una fortaleza en La Habana para proteger el puerto y el comercio marítimo, y el adelantado debía ser el encargado de la obra. En 20 de marzo de 1538 las autoridades de Sevilla recibieron orden de informarse del sitio conveniente, consultando al efecto a personas que hubieran estado en La Habana. Con especial empeño se recomendó que se evitara que la fortaleza quedase dominada por un cerro que, según los documentos de la época, estaba "cerca del puerto" 8 .
\end{abstract}

La después conocida como Fortaleza vieja fue terminada el 12 de marzo de 1540. Y afirma Irene Wright: "Estaba mal situada con relación a aquel cerro, contra el que con tanto interés había recomendado el rey se le protegiera. Este cerro era, probablemente, la llamada Peña Pobre que casi ha desaparecido con el ensanche de la ciudad"?

Siempre quedaba la posibilidad de que el innominado cerro fuese La Cabaña, el otro lado del canal de la bahía, pero en una obra anterior, al comentar el mismo documento, la propia doctora Wright la había desechado: "I do not believe that this hill was Cabaña, but, on the other hand, that it was the eminence to the west which has since almost disappeared from observation under the city itself $[\ldots],{ }^{10}$.

En 1621, diecinueve años después de que el gobernador Valdés comenzara a explotar el peñón como cantera, el Cabildo mercedeaba a Diego

7 Real ACademia Española, Diccionario de Autoridades (Madrid: Gredos, 1964), v. III.

8 I. A. WRIGHT, Historia documentada de San Cristóbal de La Habana en el siglo XVI (La Habana: Impr. El Siglo XX, 1927), t. I, pp. 14-15.

9 Ibidem, p. 17.

10 I. A. WRIGHT, The Early History of Cuba, 1492-1586 (New York: Macmillan, 1916), p. 220 . 
Pérez de Borroto un solar en el Cayaguayo para que construyera allí su vivienda ${ }^{11}$. Tampoco hay mención a colina alguna, y aunque el texto adolece de la imprecisión típica de los documentos de la época, se desprende de él que dicho paraje continuaba semidespoblado, independientemente de que ya habían sido mercedados otros solares.

$\mathrm{Al}$ parecer, la primera asignación del topónimo Cayaguayo a la colina que centra nuestra atención fue retroactiva, pues vino en 1936 de la mano del historiador Manuel Pérez-Beato, quien afirmó: "La loma se llamó del Cayaguayo, y del Cayo, nombre que se hizo extensivo al barrio en que radica" ${ }^{12}$. Como en otras ocasiones, no citaba su fuente, simplemente había que creerle o no, y algunos optaron por lo primero.

Pérez-Beato también se arriesgó a tratar de desentrañar la difícil etimología del topónimo. Para ello se basó en una supuesta analogía topográfica. Según él, en La Habana colonial existía otro lugar igualmente denominado Cayaguayo: la loma después conocida sucesivamente como de Manuel González, de Soto y, por último, de Atarés, donde en la segunda mitad del siglo XVIII fuera construida la fortaleza que aún la señorea.

[...] ambas con las mismas condiciones topográficas, que les han hecho acreedoras a tan extraña denominación.

Son dos eminencias o lomas, situadas a orillas del mar a modo de Cayos elevados $[. .$.$] a cuya particularidad debieron su nombre { }^{13}$.

De ahí extrae su definición: "Las voces guaso, guasí y guayo, corresponden en nuestra toponimia a las de orilla, Ribera, Orilla y lugar Bajo, y vale por tanto decir Cayaguaso, Cayaguasí y Cayaguayo, como: Cayo de la orilla o de la ribera" ${ }^{14}$.

Sin embargo, un destacado lingüista contemporáneo, especializado en toponimia aborigen, tiene una opinión diferente:

[...] Sin lugar a dudas, nos hallamos ante un topónimo indocubano más, como Jimaguayú, Camagüey, Cuba, Cubanacán y otros. Su filiación aruaca es induda-

11 Oficina del Historiador y Museo de la Ciudad de La Habana. Actas Capitulares del Ayuntamiento de La Habana

12 M. PÉrez-BeAto, op. cit., p. 79.

13 Ibid., p. 20. Artiles también afirma la existencia del segundo Cayaguayo, pero tampoco proporciona referencias de sus fuentes. Jenaro ARTiles, La Habana de Velázquez (La Habana: Municipio de La Habana, 1946), p. 51.

${ }_{14}$ Ibid. Anteriormente, Alfredo Zayas había recogido el nombre como el de una hipotética provincia india "en la costa Norte, entre las de Baní y Camagüey". Alfredo ZAYAS y ALFONSO, Lexicografía antillana (La Habana: Molina, 1931, 2.a ed.), t. I, p. 183. 
ble, ya que en su formación participan dos vocablos muy comunes en otras voces aruacas de uso en Cuba:

Caya-: Cayajabo (planta enredadera, Canavalia nitida, que produce semillas rojas con una lista negra en uno de sus lados y se utilizaba y utiliza para confeccionar adornos), cayama (nombre popular del ave Nycteria americana), cayari (nombre en desuso aplicado a un cangrejo rojo, pequeño, propio de agua dulce) cayaya (nombre por el cual se identifica a la nigua, Tonga penetrans, adulta y fecundada). Además, tenemos los topónimos Cayaguán, Cayaguaneque, Cayaguaní, Cayacaca, Cayajaná, Cayao.

- Guayo: nombre del instrumento que utilizaban los aborígenes cubanos para rallar la yuca y otros tubérculos. El nombre pasó a denominar otro instrumento, hecho de hojalata, pero con la misma función.

Por otra parte, yagua (Ca-yagua-yo) es otro vocablo de indudable origen aruaco insular, nombre aplicado por nuestros aborígenes a la parte superior del tronco de la palma real, voz que está presente en topónimos como Yaguaneque, voz de un río que dio origen al nombre de un pequeño puerto para embarcaciones menores, situado en la costa norte de Baracos.

A pesar de que disponemos de todos estos recursos para la comparación y definición del origen lingüístico del nombre de lugar Cayaguayo, carecemos de la suficiente información para desentrañar su significado ${ }^{15}$.

Los comentarios huelgan. Actualmente no queda vestigio del topónimo en la barriada en cuestión; aunque Pérez-Beato, que publicó su libro en 1936, afirmaba "Hasta un tiempo muy cercano, se le decía aún El Cayo, a este lugar" ${ }^{16}$.

\section{LA PEÑA POBRE}

La más antigua referencia documental a este topónimo que hemos hallado hasta ahora es la que aporta el historiador español Francisco Castillo Meléndez y data de 1670. El 6 de marzo de ese año había tomado posesión del gobierno de la Isla el almirante Francisco Rodríguez de Ledesma. Pronto se informó del viejo proyecto de circundar La Habana con una muralla y al mes siguiente, 2 de abril de 1670, escribió a Bernardo de Quirós, secretario del Rey, dando su opinión de que la ciudad no contaba con personal suficiente para la guarnición de tan extensa fortificación y en su lugar proponía como alternativa:

15 Sergio VAldÉs Bernal, Comunicación personal, 29 de diciembre de 1993.

16 M. PÉrEz-BEATO, op. cit., p. 21. Igualmente asegura que el vecino callejón de Espada también fue conocido con el nombre de Cayo, "por la loma, a cuyo pie se halla". Ibid., p. 149. 
Hacer una ciudadela en el paraje que llaman la Peña Pobre, parte eminente que domina la çiudad y el puerto y al pie della un recinto que la circunvalasse y fuese capaz de recevir en tiempo de invasión la vecindad con sus haciendas, muebles, pues amenos costa de la mitad se conseguía por este medio la seguridad que se pretende por medio de la circunvalación entera y se reparaba el daño que el enemigo podía hacer apoderándose deste parage, que era por nosotros casi irremediable ${ }^{17}$.

$\mathrm{Al}$ parecer, la propuesta del nuevo gobernador no fue tenida en cuenta, pues Castillo Meléndez no encontró "el más leve vestigio documental" de que fuese discutida o analizada en el Consejo ni en la Junta de Guerra de Indias ${ }^{18}$. Lejos de ello, el 9 de mayo de 1672, se firmó una Real Cédula aprobando el inicio de la construcción de la muralla, y el 22 de enero de 1674 - en medio de gran ceremonial, que incluyó salvas de artillería- tocó al propio Rodríguez de Ledesma colocar la primera piedra de la obra que había impugnado y que sólo sería concluida un siglo después, bajo el gobierno de Juan Francisco de Güemes y Horcasitas ${ }^{19}$.

Del hecho de que Rodríguez de Ledesma la describa como "parte eminente que domina la çiudad y el puerto" se desprende que la colina aún tenía una altura superior a la actual. Es decir, que el gobernador Pedro de Valdés no la había desbastado todo lo necesario como para eliminar de la mente de sus sucesores la preocupación por el daño que pudiera causar su captura por un hipotético enemigo. Esta inferencia se corresponde con el promontorio que aparece dibujado en los planos de la muralla fechados en $1674,1675,1677$ y $1679^{20}$.

Es probable que con posterioridad a dichos planos se haya seguido utilizando el sitio como cantera para algunos lienzos de la muralla e incluso para la propia primitiva ermita del Santo Ángel Custodio.

17 Archivo General de Indias (AGI). Santo Domingo. 452. Carta de Ledesma a Quirós, 2 de abril de 1640. Apud Francisco Castillo Meléndez, La defensa de la Isla de Cuba en la segunda mitad del siglo XVII (Sevilla: Diputación Provincial de Sevilla, 1986), p. 230.

18 Ibidem. Independientemente de que la proposición de Ledesma haya sido desestimada, es obvio que la Peña Pobre influyó en el trazado de la muralla, pues, por elementales razones militares, tenía que quedar dentro del recinto, no fuera. De cierta forma, gracias a ella la ciudad tuvo unos metros más de área.

19 Ibidem, pp. 235-236 y 261-262.

20 AGI. Santo Domingo. Mapas y Planos. N. ${ }^{\circ}$ 68, 69, 73 y 81, respectivamente. Todos están reproducidos en la citada obra de Castillo Meléndez y en el libro $L a$ Habana Vieja. Mapas y planos en los archivos de España (Madrid, 1985), publicado con motivo de la exposición de igual nombre que estuvo montada en el Castillo de la Real Fuerza, en La Habana, entre enero y marzo de 1985. 
La segunda referencia documental en orden cronológico la encontró el historiador cubano César García del Pino en el Archivo General de Indias. Data de 1691 y forma parte de un expediente sobre la fabricación de la mencionada ermita. Es la siguiente: "En el paraje que llaman de la peña pobre barrio del Cayaguayo [...]" ${ }^{21}$. Por primera vez se establece documentalmente una diferenciación entre la Peña Pobre en sí misma y el ya para entonces barrio del Cayaguayo, en el que se hallaba enclavada.

Contrariamente al topónimo Cayaguayo, el de Peña Pobre sí ha perdurado en la barriada, como nombre de una de las calles laterales de la loma, de apenas tres cuadras de largo. Obviamente, esta era la calle, camino o sendero que en su tiempo conducía a la Peña Pobre. De ahí que el uso del topónimo sobreviviera en ella cuando ya había dejado de aplicarse a la colina.

En la casa entonces marcada con el número doce de esa calle Peña Pobre —en el habanerísimo barrio del Ángel, como él mismo dijera- nació en 1903 el historiador y profesor universitario Elías Entralgo Vallina, uno de los más finos escudriñadores de nuestro pasado y de nuestra cultura.

En años más recientes, la calle Peña Pobre ha dado título y escenario a la primera novela publicada por el ensayista, poeta y crítico literario cubano Cintio Vitier, quien pone estas palabras en boca de uno de sus personajes:

No amo esta calle sólo por la historia que te he contado de mis abuelos paternos. Me parece que he nacido aquí, que todo vuelve a este sitio, pero, te repito, no sólo por la leyenda familiar. Creo que esta fascinación está unida al nombre mismo de la calle. No conozco un nombre más hermoso, y no podría decir por qué" 22.

\section{LA LOMA DEL ÁNGEL}

El obispo Diego Evelino de Compostela erigió en la cima de la Peña Pobre la ermita del Santo Ángel Custodio y la dedicó como auxiliar de la Parroquial Mayor de La Habana en $1690^{23}$.

21 AGI. Santo Domingo. Leg. 111, Ramo 2. "Testimonio de los autos fechos sobre la fabrica hecha de la Hermita del Santo Angel Custodio en la Ciudad de la Hauana..." (Cortesía de César García del Pino).

22 Cintio VITIER, De Peña Pobre; memoria y novela (La Habana: Editorial Letras Cubanas, 1980), p. 301.

23 José Martín Félix DE ARRATE, Llave del Nuevo Mundo; antemural de las Indias Occidentales (La Habana: Comisión Nacional Cubana de la UNESCO, 1964, 4." ed.), p. 178. De la Torre y Roig difieren de esta fecha. El primero afirma que fue en 1679 
Paulatinamente, los habaneros dieron en abreviar el nombre del nuevo templo, llamándole simplemente El Ángel y, por extensión, también comenzaron a llamar así a la loma, al barrio y al baluarte de la muralla construido pocos metros detrás de la iglesia.

Pero es de suponer que el viejo nombre tardó en desaparecer por completo del vocabulario popular. En 1882 Cirilo Villaverde publicó en Nueva York la versión definitiva de su novela Cecilia Valdés o la Loma del Ángel —que es casi el Baedeker de La Habana decimonónica- y al describir el sitio que da subtítulo a su obra menciona en dos ocasiones el antiguo topónimo:

A medida que se acercaban a la iglesia del Santo Ángel Custodio, que, como sabe el lector habanero, se halla asentada en la planicie de la Peñapobre [...] Como hemos dicho anteriormente, la pequeña iglesia del Santo Ángel Custodio, se halla asentada en la planicie estrecha de la Peñapobre, especie de arrecife de poca extensión, aunque bastante elevado respecto al plano general de la ciudad $[\ldots]^{24}$.

Observemos que Villaverde utiliza el tiempo presente, o sea, que casi dos siglos después de la construcción del templo aún coexistían ambos topónimos. En esta iglesia fueron bautizados dos cubanos excepcionales: Félix Varela y José Martí.

El resto, todos lo conocemos. La colina hoy está totalmente urbanizada e integrada a la vida de una ciudad moderna, pero su pintoresca plazuela semitriangular aún posee el peculiar encanto que le da el conjunto arquitectónico, dominado por la alta torre parroquial, y el haber sido escenario del dramático desenlace de la más famosa novela cubana del siglo XIX, hecho este que allí recuerda un busto de su autor.

\section{ALGUNAS PRECISIONES}

Antes de adentrarnos en el hipotético origen extralingüístico del orónimo Peña Pobre —objeto central de nuestro estudio— creemos nece-

y el segundo que en 1695; pero Arrate reproduce la inscripción latina que se colocó en aquel momento. La primitiva ermita después sería ampliada y en dos ocasiones reconstruida, a causa de desastres naturales. El edificio actual, de estilo gótico, data de mediados del siglo XIx.

24 Cirilo Villaverde, Cecilia Valdés o la Loma del Ángel (Lima: Primer Festival del Libro Cubano, s.f.), pp. 81-82. Esto contradice lo escrito por Arrate en 1761: "una colina que se llamaba vulgarmente en aquellos tiempos la Peña Pobre y en ésta la loma del Ángel", op. cit., p. 178. Al parecer, el ilustre regidor habanero se apresuró mucho en darle la extremaunción al viejo topónimo. 
sario recapitular parte de lo dicho. O sea, que hasta ahora no hemos encontrado ningún documento de los siglos XVI y XVII en el cual se designe expresamente a la colina en cuestión con el topónimo indocubano Cayaguayo. En nuestra opinión -hasta tanto no se demuestre lo contrario-, tal afirmación constituyó un error de interpretación cometido por el historiador Manuel Pérez-Beato, quien, por lo demás, tantos conocimientos útiles nos ha legado sobre nuestra historia local.

Todo hace suponer que el topónimo Cayaguayo -obviamente heredado de los aborígenes por nuestros primeros colonizadores- era aplicado a la zona boscosa que existía en la margen occidental del canal de la bahía, aproximadamente en el área comprendida actualmente entre la calle Chacón y el Paseo del Prado.

Tampoco descartamos la posibilidad de que el topónimo Cayaguayo abarcara a toda la zona, loma incluida. Lo que no parece lógico, ni hay indicios de ello, es que designara expresamente a la colina. De haber sido así, no aparecería mencionado en las mercedes de solares del Cabildo habanero. ¿Por qué construir una casa en un promontorio rocoso habiendo tierra llana y realenga alrededor?

Ya vimos que en 1602 el gobernador Valdés lo llamaba "el padrastro del Cayaguayo". Es decir, se trataba de un promontorio sin nombre o, al menos, sin nombre oficial que, como tal, fuese digno de ser consignado en la documentación destinada a la Corte. No olvidemos que Arrate precisa que Peña Pobre era un topónimo de uso vulgar.

Ahora bien, cuando el gobernador Rodríguez de Ledesma se decide a mencionar este topónimo en su carta de 1670 , de su texto se infiere que para entonces ya era de antigua data, no de reciente acuñación. Esto deja abierta la posibilidad de que haya comenzado a usarse a principios del siglo xvII o aún dentro de los límites cronológicos del siglo xvI.

Somos de la opinión, por razones que explicaremos más adelante, de que su empleo se inició en la segunda mitad del siglo xvI y que desde entonces coexistía con el topónimo Cayaguayo, asignado primeramente al bosque y después al barrio adyacente al promontorio, tal y como fue recogido en el citado expediente de 1691.

Para nosotros, el enigma siempre estuvo en el nombre mismo, sobre todo por el uso del adjetivo calificativo "pobre". Si como afirman Camps y Norona, los topónimos compuestos por un sustantivo y un adjetivo "sugieren características físico-geográficas del lugar denominado" ${ }^{25}$, ¿qué es

25 Alina M. CAmps Iglesias y María Teresa NOROÑa VILÁ, Aproximación al estudio de la toponimia cubana (La Habana: Academia de Ciencias de Cuba, Instituto de Literatura y Lingüística, s.f.), p. 39. 
una peña pobre? La explicación había que buscarla en factores culturales exógenos.

\section{DE NOVELAS Y LECTORES}

La primera mitad del siglo xvi fue el periodo de máxima difusión en España y el resto de Europa de las novelas de caballería, género que Gabriel García Márquez ha definido como "delirio literario". Nadie ha sintetizado mejor que don Marcelino Menéndez y Pelayo los contenidos típicos de esta literatura:

La desenfrenada invención de los libros de caballerías; con su falta de contenido histórico; con su perpetua infracción de todas las leyes de la realidad; con su geografía fantástica; con sus batallas imposibles; con sus desvaríos amatorios [...], con su disparatado concepto del mundo y de los fines de la vida; con su población inmensa, de gigantes, enanos, encantadores, hadas, serpientes, endriagos y monstruos de todo género, habitadores de ínsulas y palacios encantados; con sus despojos y reliquias de todas las mitologías y supersticiones del Norte y del Oriente ${ }^{26}$.

El consumo de estas obras fue extraordinario y se extendió a todas las clases y capas sociales. Madariaga nos ha proporcionado un impresionante inventario de personalidades europeas de los siglos XVI-XIX aficionadas a su lectura ${ }^{27}$. Pero nos interesa básicamente su aceptación entre las capas humildes de la población, los hombres y mujeres que Alfonso Reyes clasificaba en la categoría más baja de lectores, "el sencillo pueblo", el que más experimenta "el deleite de leer" y, por ende, "la lectura se le vuelve vida".

En horas robadas, el hombre humilde lee con fruición y se queda con la sustancia, con el asunto y con las mejores palabras: nada más. Puesto a la prueba del recuerdo, sólo ha conservado las esencias. Él no sabe el nombre del libro ni el nombre del autor, caso típico de la impresión humana que aún no llega a la lite-

26 Marcelino MenÉNDEZ y PELAYO, "Cultura literaria de Miguel de Cervantes y elaboración del Quijote", San Isidoro, Cervantes y otros estudios (Madrid: Espasa-Calpe, 1959, 4." edición), p. 109. Independientemente de su difusión continental, "lo cierto es que ningún pueblo como el de España transformó el espíritu animador de la novela andantesca en carne y tuétano de su carácter nacional". Mirta AGUiRRE, Un hombre a través de su obra: Miguel de Cervantes Saavedra (La Habana: Editorial Letras Cubanas, 1979, 2." ed.), p. 22.

27 Salvador DE MADARIAGA, Guía del lector del Quijote (Buenos Aires: Editorial Sudamericana, 1967, 6. ${ }^{a}$ ed.), p. 46. 
ratura. "¿Has leído — dice— la historia de un paladín a quien se le moría el caballo todos los martes?" 28 .

Era ese pueblo quien con más asiduidad y credulidad asimilaba aquellos monumentos a la desmesura. Salvador de Madariaga lo ha explicado así:

\begin{abstract}
El pueblo busca ante todo en la literatura una distracción a la monotonía de su vida. La gente del pueblo no dispone de gran poder para moldear su propia vida, y rara vez ejerce su voluntad en empresas de mucho momento. Es, pues, natural que se complazca en libros que cuentan de héroes ante cuya potente voluntad se parten los gigantes como sandías y los castillos se vienen abajo como si fueran de naipes, y que, en contraste con su propia vida de obstáculos siempre renovados, halla satisfacción leyendo cuentos en los que los trabajos tienen fin y todo el mundo termina por descansar en una felicidad sin nubes.

Los libros de caballería eran, pues, el melodrama de la época, con esta ventaja: que como aquella época sabía menos cosas concretas que la nuestra, era mayor el campo que dejaba a la imaginación ${ }^{29}$.
\end{abstract}

Afinando más la pupila crítica sobre sus compatriotas, Ángel del Río ve en la "inmensa fortuna" de este género una "muestra de la apetencia por lo excepcional que alimentaba la fiebre de aventuras de los españoles", quienes los leían "probablemente no para escapar de la realidad [...] sino para satisfacer su sed de lances extraordinarios" ${ }^{30}$.

Cervantes ha descrito magistralmente esa popularidad en el capítulo XXXII de la primera parte del Quijote. Para Maritornes, las escenas amorosas de tales novelas son "cosa de mieles" y el ventero lleva su fanatismo al extremo de proclamar su convicción acerca de la absoluta veracidad histórica de todo lo narrado en ellas.

En la abundante producción que nos legó aquel género descuella el Amadís de Gaula, que Jean Cassou considera "una obra maestra de la novela de caballería" ${ }^{31}$, "la síntesis, en una forma artística, y todavía no mecánica y vulgarizada, de todos los aspectos bajo los cuales una edad nueva sueña con la edad precedente" ${ }^{32}$. El propio Cervantes la salva de ir a la hoguera en el "donoso y grande escrutinio" y afirma, por boca del barbe-

28 Alfonso REYES, "Categorías de la lectura", Obras completas (México: FCE, 19551992), t. XIV, p. 159.

29 S. DE MADARIAGA, op. cit., pp. 42-43.

30 Angel DEL Río, Historia de la literatura española (La Habana: Instituto del Libro, 1968), v. I, pp. 146-147.

31 Jean CASsOU, Cervantes; un hombre, una época (La Habana: Editorial Nacional de Cuba, 1966), p. 72.

32 Ibidem, p. 73. 
ro, "que es el mejor de todos los libros que de este género se han compuesto" ${ }^{33}$.

Su difusión fue grande y se dilató en el tiempo. Leonard la considera "la primera novela realmente popular que circuló impresa" ${ }^{34}$. Existe una anécdota, muchas veces citada, que sintetiza cuánto caló en el gusto y la sensibilidad del público lector de la época. La tomamos de don Marcelino Menéndez y Pelayo:

Don Francisco de Portugal, en su Arte de galantería, nos habla de un caballero de su nación que encontró llorando a su mujer, hijos y criados; sobresaltóse, y preguntóles muy congojado si algún hijo o deudo se les había muerto; respondieron, ahogados en lágrimas, que no; replicóles, más confuso: "Pues ¿por qué lloráis?". Dijéronle: "Señor: hase muerto Amadís" 35.

\section{LA CABALLERÍA EN AMÉRICA}

En 1949 el profesor Irving Leonard culminó una labor investigadora de muchos años con la publicación de su Books of the Brave ${ }^{36}$, ya devenido en un clásico de la historiografía sobre la cultura en la América Hispana. Uno de los propósitos de la obra es "explorar la posible influencia de una forma popular de literatura sobre la mente, la conducta y los actos de sus contemporáneos españoles en el siglo XVI" ${ }^{37}$. El autor profundiza en la importancia de "las frecuentes y sutiles interacciones entre la literatura y los hechos humanos" y nos demuestra cómo a veces "manifestaciones inferiores de la expresión artística [...] por circunstancias especiales, remueven las emociones de sus lectores de un modo más profundo" y se convierten en "instigadores inconscientes de las acciones del hombre, al condicionar sus actitudes y sus reacciones" ${ }^{38}$.

33 Don Quijote de la Mancha. Primera parte. Capítulo VI.

34 Irving A. LEONARD, Los libros del Conquistador (La Habana: Casa de las Américas, 1983), p. 27.

35 M. MENÉNDEZ Y PELAYO, op. cit., p. 119.

36 Irving A. LEONARD, Books of the Brave. Being an Account of Books and Men in the Spanish Conquest and Settlement of the Sixteentb-Century New World (Cambridge, Mass.: Harvard University Press, 1949). La primera edición en español fue publicada en 1953 por el Fondo de Cultura Económica en una traducción de Mario Monteforte Toledo, revisada por Julián Calvo, con el título de Los libros del Conquistador. La misma traducción fue publicada en Cuba, treinta años después, por la Casa de las Américas, sin dar crédito a los traductores y sin incluir los apéndices documentales de la obra. Esta es la edición que hemos utilizado y por la cual citamos. Ver nota 34.

37 I. H. LEONARD, op. cit., p. 12.

38 Ibid., p. 11. 
Leonard aborda concretamente el papel desempeñado de manera indirecta por las novelas de caballería en la conquista de América, al constituir buena parte del bagaje cultural de los hombres que acometieron aquella singular empresa.

Si la población de los centros más cultos, y por consiguiente en mayor contacto con las corrientes espirituales e intelectuales del Renacimiento, era tan receptiva para las fantasías de ese género, no se podía esperar que el tosco y ordinario conquistador, que se abría paso por el interior de oscuros y misteriosos continentes, saliera de la influencia de lo maravilloso que dominaba su mente ${ }^{39}$.

Predispuestos por la aceptación de los milagros de su fe religiosa, por la poesía y el mito de la Edad Media y por las crónicas de las fabulosas hazañas de sus ancestros en sus luchas contra los invasores sarracenos, los españoles absorbieron las exuberantes creaciones de los escritores con una credulidad y una convicción tan espontáneas que parecen imposibles a una mentalidad moderna ${ }^{40}$.

Hasta un escritor como Gabriel García Márquez, en cuyos cuentos y novelas el realismo se entremezcla con la más poética fantasía, nos deja constancia de su asombro ante la conducta de aquellos hombres:

Acostumbrado a unas novelas donde había ungüentos para pegarles las cabezas cortadas a los caballeros, Gonzalo Pizarro no podía dudar cuando le contaron en Quito, en el siglo Xvi, que muy cerca de allí había un reino con tres mil artesanos dedicados a fabricar muebles de oro, y en cuyo palacio real había una escalera

39 Ibid., p. 58. En realidad, las fuentes literarias de los estímulos de orden fantástico que bullían en las mentes de los conquistadores y primeros colonizadores eran más amplias que las provenientes de las novelas de caballería, género al que necesariamente se constriñe Leonard. Para una buena síntesis, puede consultarse: Georg FRIEDERICI, El carácter del descubrimiento y de la Conquista de América (México: FCE, 1973), pp. 339-345. Este historiador atribuye la predisposición de los conquistadores hacia la fantasía, entre otras causas, a "la coexistencia que durante varios siglos mantuvieron los españoles con el pueblo que creó las historias fantásticas de las Mil y una noches" (p. 340).

40 Ibid., p. 39. Si algo se le quedó en el tintero al profesor Leonard fue un análisis de la repercusión del descubrimiento y conquista del Nuevo Mundo en el auge experimentado por la novela caballeresca en la primera mitad del siglo XVI, máxime cuando las obras más antiguas del género eran anteriores a 1492. Esa interacción entre la realidad y la fantasía sólo la hemos encontrado apuntada por la historiadora mexicana Ida Rodríguez Prampolini: "Creo que ya no causará tanta sorpresa el florecimiento de la novela caballeresca en el momento en que España realiza la conquista de las Indias. Las estrechas relaciones entre una y otra han quedado patentes de tal suerte que forman un conjunto cuya explicación debe radicarse en el alma del pueblo español tal como vivió entonces y sintió su destino". Ida Rodríguez Prampolini, Amadises de América; la bazaña de Indias como empresa caballeresca (Caracas: Centro de Estudios Latinoamericanos "Rómulo Gallegos", 1977, 2." ed.), p. 105. 
de oro macizo, y estaba custodiado por leones con cadenas de oro. ¡Leones en los Andes! [...] el tamaño de su credulidad puede medirse por la expedición que armó para buscar el reino inverosímil: 300 españoles, 4.000 indios, 150 caballos y más de mil perros amaestrados en la caza de seres humanos ${ }^{41}$.

Para el conquistador español, el encuentro con la realidad americana significó el choque de lo maravilloso imaginado con lo maravilloso no imaginado, choque en el cual se desdibujaron los límites entre ambos universos. Alejo Carpentier lo ha visto así:

Pero ahora ocurrirá algo inesperado: al iniciarse en Cuba la conquista de México, comenzarán a vivir, los compañeros y soldados de Hernán Cortés, una auténtica aventura de caballería. Igual que en sus novelas, encontrarán en tierra de México, ciudades maravillosas y desconocidas como lo era la capital de Moctezuma; reinos ignorados, como el de Tlaxcala; montañas que despedían humo, animales nunca vistos, fieras de una traza insospechada, encantadores y magos (los teules); maleficios de magia negra en la sangre de los teocalli; y, al descender hacia Las Hibueras, dragones acuáticos (los caimanes) y serpientes de un largo desmesurado [...] De asombro en asombro, los compañeros de Cortés viven su propio Libro de Caballería - un libro de caballería que aventajaba, en mucho, los que tanto hablaban de las andanzas de Amadís de Gaula y Florismarte de Hircania. Aquí el prodigio era tangible, el encantamiento era cierto, los tesoros eran visibles, los hechiceros, desfigurados por horribles mutilaciones rituales, se entregaban a escalofriantes prácticas, al compás de las ignoradas percusiones del tepnaxtle... Lo maravilloso resultaba, por vez primera, lo "real maravilloso" ${ }^{42}$.

Francisco López de Gómara, cronista de Indias, pero no conquistador, se basó en fuentes documentales y testimonios para redactar su controvertida historia de las hazañas de Cortés, que publicó en 1552. En su capítulo 181 narra el momento en que los españoles llegan ante un río crecido que no pueden vadear. Tras una exploración, descubren un providencial puente natural que Gómara describe así:

Era aquel paso una losa o peña llana, lisa y larga cuanto el río ancho, con más de veinte grietas por do caía la agua sin cubrilla; cosa que parece fábula o encantamiento como los de Amadís de Gaula, pero es certísima. Otros lo cuentan por milagro, mas ello es obra de natura, que dejó aquellas pasaderas para el agua, o la misma agua con su continuo curso comió la peña de aquella manera ${ }^{43}$.

41 Gabriel García MárQuEZ, "Fantasía y creación artística en América Latina y el Caribe" [1979], La soledad de América Latina. Selección y prólogo de Víctor Rodríguez Núñez (La Habana: Editorial Arte y Literatura, 1990), pp. 317-318.

42 Alejo CarPentier, "Nuestro primer clásico: Bernảl Díaz del Castillo", Verde Olivo, 11, 28 (julio 1978), pp. 24-25.

43 Francisco LóPEz De Gómara, Historia de la conquista de México. Prólogo y cronología de Jorge Gurría Lacroix (Caracas: Biblioteca Ayacucho, 1979), p. 282. Este 
Es decir, dada su condición de profesor de Alcalá de Henares, Gómara tiene buen cuidado de aclarar su personal certeza acerca del origen natural del paso, pero, a la vez, no puede resistirse a establecer la comparación con el libro paradigmático.

El ejemplo clásico de la popularidad de la literatura caballeresca entre aquellos hombres es el que nos brinda Bernal Díaz del Castillo en el párrafo más citado y comentado de toda su obra, a la que Alejo Carpentier considera "el único libro de caballería real y fidedigno que se haya escrito" ${ }^{44}$. El conquistador y cronista describe así el momento en que, conjuntamente con Hernán Cortés y su tropa, se acerca a Ixtalapapa:

Y desde que vimos tantas ciudades y villas pobladas en el agua, y en tierra firme otras grandes poblazones y aquella calzada tan derecha y por nivel como iba a México, nos quedamos admirados, y decíamos que parecía a las cosas de encantamiento que cuentan en el libro de Amadís, por las grandes torres y cués y edificios que tenían dentro en el agua, y todos de calicanto, y aun algunos de nuestros soldados decían que si aquello que veían si era entre sueños, y no es de maravillar que yo escriba aquí de esta manera, porque hay mucho que ponderar en ello que no sé como lo cuente: ver cosas nunca oídas, ni aun soñadas, como veíamos ${ }^{45}$.

párrafo de Gómara evidencia el error de Anderson Imbert al afirmar que Bernal Díaz del Castillo "es el único cronista que se atreve a citar novelas de caballería". Enrique ANDERSON IMBERT, Historia de la literatura hispanoamericana (México: FCE, 1961, 3." ed.), t. I, p. 35.

44 A. CARPEntier, "De lo real maravilloso americano", Tientos y diferencias (La Habana: Ediciones Unión, 1966), p. 93.

45 Bernal DíAz DEL CASTILLO, Historia verdadera de la conquista de la Nueva España. Introducción y notas de Joaquín Ramírez Cabañas (México: Editorial Porrúa, 1976, 11." ed.), p. 159. Carpentier considera este párrafo el testimonio del encuentro del europeo con lo real maravilloso americano. A. Carpentier, "Lo barroco y lo real maravilloso", Razón de ser (La Habana: Editorial Letras Cubanas, 1984), p. 77. Alfonso Reyes ha dicho sobre él: "Y nada iguala su éxtasis y arrobo a la vista de la Ilión Azteca: obra de encantamiento - dice- y sueño del Libro de Amadis". A. REYes, "Letras de la Nueva España", op. cit., t. XII, p. 319. Para Leonard es: "[...] La única mención clara de una de esas novelas, procedente de uno de los aventureros que dominaron el Nuevo Mundo" y "la prueba más concreta e importante de que los libros de caballería jugaron un papel de trascendencia en el delirio de conquista de los españoles, a pesar de lo que contra ellos hayan podido vociferar moralistas y filósofos". Op. cit., p. 65 y 70. Al parecer, Leonard no se percató de que en la propia obra de Díaz del Castillo, además de la anterior y de la mención al jactancioso Agrajes, hay otra referencia directa al Amadís de Gaula: "Bien tengo entendido que los curiosos lectores se hartarán de ver cada día tantos combates, y no se puede menos hacer, porque noventa y tres días que estuvimos sobre esta tan fuerte y gran ciudad, cada día y de noche teníamos guerra y combates; por esta causa los hemos de recitar muchas veces 
Déspués de conocer todo lo anterior es fácil comprender la inevitabilidad de que la toponimia americana conservara permanente huella de aquella afición novelesca, huella que es a la vez la prueba más concluyente de la misma.

Así el río Amazonas y la región selvática central del Brasil heredaron ese nombre de la antigua leyenda griega de las mujeres guerreras ${ }^{46}$, revitalizada en el siglo XVI por dos best sellers del género: Sergas de Esplandián (1510) y Lisuarte de Grecia (1514) ${ }^{47}$. El vasto territorio de California, actualmente repartido entre los Estados Unidos y México, debe su nombre a la imaginaria isla donde Garci Ordóñez de Montalvo situó el reino de esas mismas amazonas, en sus ya citadas Sergas ${ }^{48}$. La austral Patagonia, hoy compartida por la Argentina y Chile, recibió ese nombre por Patagón, "un monstruo con planta de hombre pero con rostro perruno" que aparece en el Primaleón de Grecia (1512) ${ }^{49}$.

Y así han quedado estos nombres en la geografía de América, diciéndole al toponomasta curioso que aquellos "nobles hidalgos" y "bravos caballeros", por los que clamara Rubén Darío siglos después, no se movían sólo por la codicia de oro y la ambición de poder.

\section{LA PENITENCIA DE BELTENEBROS}

Uno de los episodios más trascendentes del Amadís de Gaula es aquel en el que el caballero andante, desconsolado por la carta de ruptura que

cómo y cuándo y de qué manera pasaban, y no los pongo por capítulos de lo que cada día hacíamos porque me pareció que era gran prolijidad, y era cosa para nunca acabar y parecería a los libros de Amadís o Caballerías; y porque de aquí adelante no me quiero detener en contar tantas batallas y reencuentros que cada día pasábamos, lo diré lo más breve que pueda", Bernal Díaz del Castillo, op. cit., p. 346.

46 "La leyenda de las Amazonas fascinó a los griegos. La llevaron a todas partes. Creció con su expansión política, hasta que el mundo conocido se pobló con estas románticas figuras cuyo origen se había olvidado. Tan fascinadora fue la leyenda, que todavía en el siglo XVI embriagaba a los descubridores de Indias, quienes dieron nombre de Amazonas al río por cuyas riberas soñaron encontrarlas", A. REYES, "Religión griega", op. cit., t. $\mathrm{XVI}$, p. 287. Por lo demás, esto es visto como algo muy normal por los lingüistas: "La influencia que siempre han ejercido en la vida del hombre los aspectos materiales, sociales y espirituales de la cultura, se refleja de una manera singular en el proceso de nominación: muchos nombres son tomados de héroes legendarios, de la religión, de la mitología, etc.” A. M. CAMPS Iglesias y M. T. NOROÑa Vilá, op. cit., p. 21.

47 I. A. LEONARD, op. cit., p. 44-63.

48 Ibidem.

49 E. ANDERSON IMBERT, op. cit., t. I, p. 35. 
ha recibido de su amada Oriana, abandona la Ínsula Firme y se retira a hacer penitencia en un lugar llamado la Peña Pobre, con la única compañía del ermitaño Andalod y de dos sobrinos de éste. Allí cambia su nombre por el de Beltenebros, con el que lo rebautiza dicho ermitaño. La estancia de Amadís en el pintoresco paraje transcurre en medio de llantos y quejidos amorosos que prefiguran a Werther, y se desarrolla a lo largo de los capítulos 48, 51 y 52 del Segundo Libro de la obra.

El nombre Peña Pobre se repite no menos de once veces en esas páginas y el sitio es descrito así por el propio Andalod:

Un lugar muy esquivo y trabajoso de beuir, que es una hermita metida en la mar bien siete leguas, en una peña muy alta, y es tan estrecha la peña que ningún nauío a ella se puede llegar si no es en el tiempo de verano ${ }^{50}$ [...] es llamada la Peña Pobre, porque alli no puede morar ninguno sino en gran pobreza ${ }^{51}$.

Por su parte, el narrador se ocupa de agregar menciones a "la soledad y esquiueza de aquel lugar" 52 , "tan estrecho y apartado" ${ }^{33}$.

Suponemos que este pasaje tuvo mucha aceptación entre los lectores, pues Cervantes lo parodia en los capítulos XXV y XXVI de la primera parte de Don Quijote, cuando el Ingenioso Hidalgo se interna en el corazón de la Sierra Morena con el explícito fin de imitar la penitencia de Beltenebros en la Peña Pobre.

Evidentemente, en la mentalidad de muchos españoles de los siglos xVI y XVII, fueran fantasiosos o no, el nombre Peña Pobre debió convertirse en símbolo de un promontorio solitario y no debe extrañarnos que cuando contemplaran algún accidente geográfico que guardara cierta semejanza con el descrito en la novela o, al menos, con la representación que de él se hacían, surgiera la inevitable comparación y la festinada asignación antonomástica del novelesco topónimo a dicho sitio ${ }^{54}$.

50 Amadís de Gaula. Edición y anotación por Edwin B. Place (Madrid: CSIC, 1959-1962), t. II, pp. 394-395.

$51 \quad$ Ibid., p. 396.

52 Ibid., p. 397.

53 Ibid., p. 420. El mismo texto de la obra contradice la supuesta extrema estrechez del peñón, pues en él existen una ermita, dos casas, una huerta con árboles "muy espesos" y una fuente; pero sería demasiado pedirle un poco de coherencia a una novela de caballería.

54 En una somera exploración bibliográfica y cartográfica hemos localizado otros dos lugares de Hispanoamérica nombrados Peña Pobre. Uno de ellos es el barrio Peña Pobre, del municipio de Naguabo, en la isla de Puerto Rico. El otro es la colonia Peña Pobre, de la delegación Tlalpan, en la Ciudad de México. En la misma delega- 


\section{UN PEÑÓN SOLITARIO}

De la documentación de los siglos XVI y XVII que hemos citado en los dos primeros epígrafes de este artículo se infiere una imagen aproximada de la forma que tuvo el promontorio o padrastro de la margen occidental de la bahía habanera antes de ser explotado como cantera. Esta imagen presenta semejanzas y desemejanzas con la descripción literaria de la ficticia Peña Pobre que aparece en el libro segundo de Amadís de Gaula. A saber:

- No está en una isla a siete leguas de la costa, pero se alza a unos metros de la ribera de la bahía y del litoral norte, fácilmente divisable desde el mar, y es la única elevación del terreno en esa orilla.

- Quizás no fuera tan alta y estrecha como aquella en que moraban Andalod y sus sobrinos, pero de lo que no cabe duda es de que su altura original era muy superior a la actual. Además, tenía forma de peñón, según aparece en los mapas ya citados.

- Contrariamente al paraje novelesco, no existía allí ninguna ermita antes de 1690.

— La "soledad y esquiveza" del lugar sí coinciden, al menos durante el siglo XVI.

O sea, independientemente de las desemejanzas señaladas, una mente imbuida de literatura caballeresca, conocedora del mencionado episodio del Amadis, bien podía priorizar las semejanzas, establecer una comparación entre la realidad y la ficción y, a sabiendas de que no era ni podía ser el lugar descripto en la novela, bautizarlo profanamente con el topónimo utilizado en ella.

Dadas las premisas antes expuestas - sobre todo lo concerniente a la procedencia de los topónimos Amazonas, California y Patagonia- y basándonos en el principio de analogía histórica, consideramos que este fue el origen del topónimo habanero Peña Pobre.

Ahora bien, ¿se leían novelas de caballería en La Habana del siglo Xvi? Según Leonard, el evidente conocimiento de estas novelas por parte de los conquistadores:

Permite suponer que desde un principio podían encontrarse tales obras de ficción en las Antillas, especialmente en Santo Domingo y Cuba, que era de donde procedía buena parte de las expediciones hacia la tierra firme. La multitud de

ción, pero en la colonia Toriello, existe la calle Peña Pobre, de unas cinco cuadras de largo, cerca del Estadio Azteca. 
colonos que vivían ociosos en esas islas gracias al trabajo de indios y de negros, tenian de sobra oportunidades para hojear las fascinantes páginas de los libros que importaban los dinámicos comerciantes, y sin duda las descripciones de tierras exóticas avivaron el deseo de estos inquietos españoles de penetrar los secretos de la fabulosa tierra firme, de donde partía toda clase de rumores y cada vez en mayor abundancia ${ }^{55}$.

Acerca de esta deducción de Leonard, y en lo que a Cuba respecta, solamente ha sido localizada hasta ahora una prueba documental, y se la debemos a César García del Pino. El 6 de octubre de 1600 tuvo lugar en La Habana la venta de un lote de libros. Entre ellos figuraban cuarenta y siete ejemplares de la Historia de Carlo Magno y de los doce Pares (1525), obra francesa que, al decir del propio Leonard, fue "la invención caballeresca que gozó de mayor longevidad en la América hispana" ${ }^{56}$.

No olvidemos que la mayoría de los pobladores de La Habana provenía de España y, por tanto, eran portadores de los gustos y aficiones literarias allá vigentes y, quizás, de los propios libros ${ }^{57}$.

También hay documentación probatoria de que en 1607 ya se había establecido en la ciudad un librero de origen portugués ${ }^{58}$.

Asimismo, hemos de tener en cuenta otro factor muy importante: al menos desde 1541 La Habana era punto de reunión de las primeras flotas de la Carrera de Indias ${ }^{59}$, y, a causa de ello, en el verano de 1550 se

55 I. A. LEONARD, op. cit., pp. 83-84.

56 César GARCía del PINO, "El libro en Cuba en los siglos XVI y XVII" (Artículo en prensa). I. A. LEONARD, op. cit., pp. 58 y 225.

57 En realidad, es muy escasa y fragmentaria la información de que disponemos sobre el nivel de instrucción pública en La Habana del siglo xvı. No obstante, se sabe que a fines de ese siglo ya existían en la villa no menos de tres "maestros de escuela", dos de ellos pagados por el Cabildo. A esto se añadía la fundación de los conventos de San Francisco y Santo Domingo, y la certeza de que los vecinos más acomodados contrataban preceptores privados para sus hijos o los enviaban a estudiar a España. Cfr. GARCía DEL PINO y Alejandro DE lA FuENTE GARCía, "Introducción a la cultura en Cuba en los siglos XVI y XVII. Elementos para un nuevo enfoque", Revista de la Biblioteca Nacional José Martí, 31, 2 (1989), pp. 14-15. Los monasterios americanos de las órdenes mendicantes impartían "la enseñanza primaria, corriente en España, que incluía aprender a leer, escribir, contar, cantar y en ocasiones tocar algún instrumento musical y ayudar a decir misa". Georges BAUDOT, La vida cotidiana en la América española en tiempos de Felipe II. Siglo XVI (México: FCE, 1983), p. 311.

58 C. García del Pino y A. DE la Fuente García, op. cit., p. 25.

59 I. A. WRIGHT, Historia documentada de San Cristóbal de La Habana en el siglo $X V I$, t. I, p. 14. La frecuencia de las flotas fue normada en agosto de 1543. Cfr. Clarence H. HARING, Comercio y navegación entre España y las Indias en la época de los Habsburgos (México: FCE, 1939), p. 251. 
convirtió de hecho en la capital de la Isla, al fijar en ella su residencia el gobernador Gonzalo Pérez de Angulo ${ }^{60}$. Ya en 1553 Carlos V afirmaba que "dicha uilla hera la confluencia de los negocios de la dicha ysla por los muchos nauios que ordinariamente allí ocurrian asi de la nueva españa como del nombre de dios e cartagena y santa marta e prouincia de honduras" ${ }^{61}$. Y en 1556 el monarca se refiere a su puerto como "la escala principal de las Indias" ${ }^{62}$, lugar de tránsito obligado de todos los que viajaban a la metrópoli desde los dominios españoles de América, lo que hacía de La Habana, durante parte del año, una especie de pequeña Babel.

Cualquiera de estos hombres, mujeres o adolescentes que allí convergían, vecinos o estantes, viajeros o tripulantes de las flotas, pudo ser el primero en fijarse en aquel peñón solitario que se alzaba a pocos metros de la ribera, apreciable a simple vista desde la cubierta de los navíos, hallarle semejanza con aquel otro peñón imaginario donde hiciera penitencia su héroe literario favorito e iniciar así la espontánea costumbre de llamarle la Peña Pobre. Lo demás lo haría el tiempo ${ }^{63}$.

Por tanto, en nuestra opinión, en la segunda mitad del siglo XVI existían las condiciones físico-geográficas, por un lado, y culturales, por otro, para que el peñón en cuestión comenzara a ser denominado la Peña Pobre, como alusión al lugar ficticio que sirve de escenario a uno de los episodios del Amadís de Gaula ${ }^{64}$.

60 Ibid., p. 20.

61 ACAdEmia DE LA Historia DE CuBA, Papeles existentes en el Archivo General de Indias relativos a Cuba y muy particularmente a La Habana (La Habana: Impr. El Siglo XX, 1931), t. I, p. 200.

62 Ibid., p. 204.

63 "En los nombres de lugar se refleja la cultura y la vida social del colectivo. Por ello, las investigaciones toponomásticas ayudan a revelar los procesos sociales y por lo tanto deben ser consideradas en los trabajos sociológicos". A. V. SuPERANSKAIA, Obschaia Teoria Imeni Sobstvennogo (Moscú, 1973). Apud. A. M. CAMPS IgLESIAS Y M. T. NOROÑa VILÁ, op. cit., p. 22.

64 Sobre los lugares denominados Peña Pobre en México y Puerto Rico no disponemos de más información que la consignada anteriormente; pero no nos extrañaría que en el origen de ambos topónimos hayan concurrido factores físico-geográficos y culturales similares a los que presuponemos en La Habana de la segunda mitad del siglo XVI. Algunos alegarán, y con razón, que para ese momento ya el género caballeresco había decaído en el favor del público lector, que se había vuelto hacia la novela pastoril, el romancero y las comedias. Pero decadencia no quiere decir desaparición inmediata. Según la cronología de Henry Thomas -que reproduce Leonard-, entre 1551 y 1602 aparecieron doce nuevas novelas de caballería. En lo que respecta específicamente al Amadis, Leonard afirma que fue uno de los libros que siguieron siendo populares a lo largo del siglo. I. LEONARD, op. cit., pp. 34, 69 y 161. 
Sabemos que toda hipótesis requiere de verificación. Hasta aquí nos hemos limitado a plantearla. La única comprobación posible sería la aparición en algún archivo español de un documento de la época que demostrara lo correcto de nuestro razonamiento; pero no esperamos que esto ocurra.

Las constantes diatribas de los moralistas de aquel siglo - como Juan Luis Vives y fray Antonio de Guevara- contra las novelas de caballería, probablemente cohibieron a sus lectores de manifestar por escrito sus gustos literarios ${ }^{65}$. A esto se añaden las reiteradas prohibiciones de la Corona - siempre burladas por impresores y comerciantes- de que circulara en América toda literatura de ficción capaz de distraer a indios y mestizos de sus lecturas devotas ${ }^{66}$.

De ahí que nunca haya aparecido ninguna prueba documental de que el topónimo Amazonas provenga de una leyenda griega retomada en las Sergas de Esplandián y el Lisuarte de Grecia, de que la vasta California haya heredado ese nombre de las mismas Sergas, ni de que la extensa Patagonia fuese denominada así por un monstruo con cara de perro que es uno de los personajes de Primaleón de Grecia. Es decir, no ha sido probado documentalmente algo que nadie duda.

Otro tanto sucederá con el topónimo Peña Pobre. Esta hipótesis sólo podrá ser aceptada por consenso, sobre la base de su grado de racionalidad y verosimilitud. Es lógico que a lo largo del siglo Xvi americano la literatura caballeresca proporcionara topónimos no sólo para importantes accidentes o zonas geográficas, sino también para los pequeños o de menor relevancia. Su identificación es tarea para los lingüistas e investigadores históricos. Esta también sería una forma de comprobación de nuestra hipótesis.

Don Miguel de Unamuno nos exhortaba a "buscar lo eterno en el aluvión de lo insignificante" ${ }^{67}$, y nosotros lo vemos representado en este simple topónimo que nos habla cuando la Historia calla. Vemos condensado en él ese ingrediente de fantasía consustancial a la especie humana, esa "hambre de ficción", como la define Mario Vargas Llosa, que también tenía que estar presente - ¿cómo no iba a estarlo? - en una villa colonial de las Antillas, aunque ningún documento de la época nos lo diga. Creemos, pues, que fue la capacidad de soñar de aquellos habaneros la que dejó su huella en ese topónimo, asignado a una colina, que la suerte ha

65 I. A. LeONARD, op. cit., pp. 67 y 70.

66 Ibid., pp. 73-77.

67 Miguel DE UNAMUNO, "En torno al casticismo", Obras selectas (Madrid: Editorial Pléyade, 1946), p. 17. 
querido que sobreviva en una calle. ¿Por qué extrañarnos?. Al fin y al cabo, ya cierto inglés, contemporáneo de nuestro Cervantes, nos había advertido que "somos de la misma materia de que están hechos los sueños".

ENRIQUe LÓPEZ MESA

El autor trata de la toponimia que ha recibido desde el siglo XVI una conocida colina de la Habana vieja, llamada alternativamente "El Cayaguayo", "La Peña Pobre" y "La Loma del Ángel”. De los tres nombres, el segundo es el más enigmático. El autor llama la atención sobre la influencia de las novelas de caballerías entre los conquistadores y los primeros colonos españoles en América, y argumenta que el nombre de "La Peña Pobre" puede estar basado en un episodio del Amadis de Gaula; de la misma manera que el nombre de California procede de la novela Sergas de Esplandián, basada en el mito clásico de las amazonas.

The author discusses the three names given since the 16th century to a well-known hill in Old Havana: "El Cayaguayo", "La Peña Pobre" and "La Loma del Ángel". The second name is the most enigmatic. By calling attention to the influence of chivalry novels among the Spanish conquerors and first settlers of the Americas, the author argues that "La Peña Pobre" was named after an episode of the novel Amadis de Gaula, in the same way as the name California was taken from the novel Sergas de Esplandian, based on the classical myth of the Amazons. 